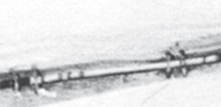




\section{Tadeu Chiarelli}

\section{Uma resenha, mesmo que tardia: \\ Roberto Pontual e a sobrevida da questão da identidade nacional na arte brasileira dos anos 1980}

palavras-chave: arte brasileira; crítica de arte; anos oitenta no Brasil; identidade nacional na arte brasileira;

Roberto Pontual; José Leonilson; Leda Catunda

keywords: Brazilian art; art criticism; 1980s in Brazil; Brazilian identity within Brazilian art; Roberto Pontual; José Leonilson; Leda Catunda
Partindo do panorama traçado pelo crítico carioca Roberto Pontual em Explode Geração!, livro publicado em 1985, pretende-se analisar em que medida a questão da identidade brasileira na arte realizada no país encontrou respaldo na cena dos anos 1980, momento em que a produção de uma jovem geração de artistas foi alinhada à tradição do barroco brasileiro, tradição esta que, segundo o crítico, perpassaria e alinhavaria alguns dos trabalhos do período, fornecendo-lhes uma espécie de chancela de uma brasilidade insuspeita, a despeito de todo contato que travavam com a arte internacional. Esta "resenha tardia" propõe-se tão somente indicar caminhos possíveis para futuros estudos mais detalhados acerca de tal questão.

Departing from the broad outlook delineated by the Brazilian (born in Rio de Janeiro) art critic Robert Pontual in his book Explode Geração!, published in 1985, this article intends to assess to what extent has the issue of Brazilian identity within art production in the country found resonance amid the artistic scene of the 1980s, a moment in which the production of a younger generation of artists who had been aligned to the tradition of the Brazilian barroque, a tradition that, according to the critic, would cut through and bring together some of the artworks of that period, bestowing upon them a token of unsuspected Brazilianness, in spite of all the contacts and links established among them and the art produced in the international sphere. This "late review" is a mere attempt to pinpoint some pathways for future more detailed studies about the matter. 
1. Dentre os estudos sobre esses assuntos, destacaria, entre outros: SANTOS, Carlos Marques dos. A invenção do Brasil. Ensaios de história e cultura. Rio de Janeiro: Ed.UFRJ, 2007; ZILIO, Carlos. A querela do Brasil. A questão da identidade da arte brasileira. Rio de Janeiro: Relume Dumará, 1997.

2. PONTUAL, Roberto. Explode Geração! Rio de Janeiro: Editora Avenir, s/d.

3. Sobre o assunto, consultar: CHIARELLI, Tadeu. Leda Catunda. São Paulo: Cosac\&Nayf, 1999.
Dentro dos estudos sobre a busca de identidade brasileira na arte, existem pesquisas que procuram encontrar sua origem, as manobras para a sua superação, além de análises que atentam para a sedimentação desse problema ainda na primeira metade do século passado ${ }^{1}$. Não obstante, faltam estudos que façam a averiguação das tentativas de superação desse problema no âmbito da produção das últimas décadas do século $\mathrm{XX}$, assim como análises que detectem sua sobrevida nesse mesmo período.

Foi dentro do interesse sobre a sobrevivência da questão do nacional na arte brasileira contemporânea que surgiu a necessidade de recuperar o livro publicado pelo crítico carioca Roberto Pontual, em 1985, Explode Geração! ${ }^{2}$. Nele são perceptíveis estratégias para legitimar aqueles jovens artistas que então surgiam para, supostamente, o reavivar da "antiga chama" da produção de uma arte nacional "legítima”, apesar de todos os contatos internacionais com os quais contava essa produção.

Refletir sobre Explode Geração! trará, sem dúvida, uma outra compreensão sobre como, na história da arte do país, a questão da identidade brasileira na arte encontra um reforço significativo na cena dos anos de 1980 - com reflexos perceptíveis até os dias de hoje. Espécie de "resenha tardia" (mas necessária) do referido livro, o texto que segue tem por objetivo introduzir no debate acadêmico sobre a arte produzida no país um discurso que, embora absorvido, ainda não foi devidamente analisado. É claro que, como "resenha”, este artigo não pretende esgotar o assunto tratado, mas lançar possibilidades de futuros estudos mais completos sobre as questões que Explode Geração! aborda.

A produção artística surgida na primeira metade dos anos de 1980, além de conseguir o apoio imediato da mídia, do mercado e das instituições ${ }^{3}$, recebeu uma tentativa de inserção imediata e definitiva no terreno da história da arte brasileira, a partir do livro Explode Geração!, de Roberto Pontual.

Com pouca ressonância na época, o livro, no entanto, reveste-se de importância sobretudo pelo fato de - visto à distância de mais de duas décadas - representar os pontos de vista de um porta-voz de expressiva parcela da crítica de artes visuais brasileiras da segunda metade do século XX.

Para inserir os artistas da "Geração 80" no âmbito maior da história da arte local, Pontual traça um panorama particular da arte do país, desde o advento do Ato Institucional número 5, emitido em 1968 pelos militares, até a segunda metade dos anos de 1970:

[...] nos dois polos do que vai aproximadamente de 1968 a 1976, a troca de sangue começa a unir os opostos. Num primeiro momento, as pressões crescentes do regime empurram os artistas da época, que ele (o regime) tenta inutilmente adotar (filho adotivo é aquele que se pega no 
4. PONTUAL, Roberto. Op.cit., p. 48-49. meio do caminho), a uma atitude de rejeição pelo desafogo. Buscando o descompromisso total, a arte sai de seus recintos fechados para gritar na rua como o resto da gente. Já aí, porém, o antagonismo armava uma relação direta, uma rede de proximidades e entramamento, típicas de uma situação de mando. $\mathrm{O}$ pai puxava as rédeas, mesmo que filhos seus realmente ainda não existissem. A situação muda aos poucos de figura, na medida em que à repressão vem somar-se o "milagre". Dessa ambiguidade sofrem os quase filhos que se lançaram no experimentalismo de meados da década de 70. Eram certamente contra o estado de coisas vigentes, mas, para contestá-lo com os seus próprios meios, não encontravam outra tática senão a da estocada indireta, de voz baixa e grave, da irritação e da raiva que transitam pela metáfora. Frustrado o grito na rua, voltam para o interior do museu. Ali, sob a sombra terrível do pai, se sentem fortes inclusive para negá-lo. Negam-no, até onde podem, pela arma exclusiva da razão. A emoção se dilacera [...] .

O crítico articula seu panorama da arte brasileira, entre 1968 e 1976, dividindo-o em dois grupos. O primeiro, aquele agrupamento de artistas ligados às tendências neofigurativas e da nova objetividade brasileira que, segundo Pontual, deixam os "recintos fechados" - ou seja, o circuito da arte - para, junto com o "povo", gritar contra o regime militar, nas ruas.

O segundo agrupamento, por sua vez, teria sido formado quando, ao recrudescimento do regime autoritário, soma-se o "milagre" brasileiro. Dentro desse contexto, esses novos artistas retornam ao circuito para, ali protegidos, negar o regime.

Para Pontual, é como se os artistas que emergiram nos anos de 1970 tivessem interiorizado a repressão do estado brasileiro, o que os teria levado a produzirem obras destituídas de qualquer espécie de emoção ou subjetividade. Por outro lado, o trecho não é capaz de esconder certa ironia por parte do autor quando se refere ao fato de que esses artistas se opunham ao poder, "protegidos", por assim dizer, pela "sombra terrível do pai".

Os estudos sobre a arte brasileira dos anos de 1970 apenas se iniciam e, portanto, é difícil saber, hoje, quais as verdadeiras motivações que levaram Pontual a sintetizar de tal maneira a produção artística daquela década, ignorando, ou não enfatizando com a devida insistência, que muitos dos artistas que emergiram naquela década deram, de fato, uma guinada, desviando-se propositadamente de certos postulados da arte aqui produzida nos anos de 1960. Mas não propriamente, ou não apenas, pelos motivos levantados pelo autor.

$\mathrm{O}$ que se percebe na produção de alguns dos principais artistas que ganharam espaço naquele período (entre eles, Waltercio Caldas, José Resende, Anna Bella Geiger, Regina Silveira e outros) é que eles não possuíam a credulidade que caracterizou a geração que os antecedeu. Informados pelas tendências internacionais da época (não apenas no campo da arte, em que 
5. Refiro-me aqui à tradição desestabilizadora das vanguardas históricas.

Sobre o assunto consultar: BÜRGER,

Peter. Teoria de la

vanguardia. Barcelona: Edicions 62, 1987.

6. Ibidem, p. 49. ganhavam força as vertentes conceituais, mas também nas áreas da filosofia e da teoria da informação), eles tinham claro que a arte não é, ou não deveria ser apenas, a arena para o extravasamento de subjetividades ou de protestos emocionais e emocionados contra o sistema. Tinham claro que a arte é um sistema dentro de um sistema maior. Assim, qualquer atividade emocional ou de protesto - por mais radical que pudesse parecer -, corria o risco de, mais facilmente, vir a ser apropriada pelo sistema maior que a continha. $\mathrm{E}$ sabiam, igualmente, que qualquer trabalho de arte, para continuar dentro de uma tradição desestabilizadora ${ }^{5}$, devia estar consciente desse problema, tornando-o justamente sua mola propulsora.

Pontual, no entanto, faztabula rasa dessas questões e, negligenciando a contribuição mais amadurecida desses artistas, prefere colocar a nova geração que surgia - a "Geração 80" - como seu antípoda.

Usando sempre a mesma metáfora psicanalítica, o autor assim define os artistas que elegeu como pertencentes a uma espécie de geração redentora da arte do país:

[...] Os artistas que compõem a geração de agora são, enfim, filhos plenos desse pai rude, severo, atrabiliário e manchado de sangue como um personagem de Shakespeare, que 1964 impôs por arquétipo [...]. Praticamente todos eles eram crianças de colo ou, no máximo, meninos pré-adolescentes quando o ciclo militarista teve início. Dele é que receberam o leito, o puxão de orelha e a cartilha. E hoje, quando começam a falar por si próprios, podem encarar o pai com inteiro conhecimento de sua figura. Podem mesmo contrariá-lo profundamente, levando às últimas consequências a abertura que ele lhes propôs como trégua e sendo, na hora aguda da crise, a perfeita encenação das diretas já. Estão além e por cima da anistia $[. . .]^{6}$.

Alçados praticamente à condição de heróis da abertura política que se anunciava, restava ainda a Roberto Pontual conceder aos artistas dessa geração foros de uma brasilidade insuspeita, brasilidade esta que o autor não percebia na produção dos artistas surgidos na década anterior.

Pontual vai se referir ao "estilo" da "Geração 80" da seguinte maneira:

[...] Assim, em primeira instância, o estilo da Geração 80 se tece com uma série de nadas: nada de frieza, nada de olimpismo, nada de altas teorias, nada de conceituação abusiva, nada de fotografismo [...], nada de isolamento, nada de hegemonia entre cariocas e paulistas, nada de patrulhismo, nada de porra-louquice. Nada de exclusões ou de proibições. Nada, portanto, de um só estilo. A mesma pluralidade de reencontros de que falava Bonito Oliva para explicar o estilo de sua transvanguardia. Degelo, pragmatismo, diálogo, consenso, liame, acúmulo, companheirismo, são algumas das palavras que bem a balizam. O que confere à Geração 80 o seu autêntico tom é esse misto de idealismo (disciplina íntima) e de romantismo (anseio de aventura) que faz a grande força do barroco. Eis a primeira conclusão a retirar 
8. Termo cunhado pelo crítico e curador italiano

Achile Bonito Oliva

para definir, primeiro,

parte da pintura italiana da passagem dos anos de 1970 para a

década seguinte e, na

sequência, parte da

pintura internacional do

mesmo período. Para o

crítico, muitos artistas

italianos e internacionais abandonavam a

crença num suposto “darwinismo", presente na pintura de vanguarda,

para praticarem uma

pintura que transitava livremente pelos vários estilemas identificadores dos movimentos de vanguarda anteriores, assim como das outras épocas da arte do passado. Sobre o assunto ler OLIVA, Achile Bonito. “The international TransAvanduarde", Flash Art, n.104, 1991.

9. Voltarei a tratar deste assunto.

10. Sobre a referida exposição, consultar:

PONTUAL, Roberto

(Coord.). América Latina.

Geometria Sensível (Catálogo de Exposição). Rio de Janeiro: Jornal do Brasil Ltda, 1978.
Ocríticoestabeleceumaestratégiainteressanteparajustificarevalorizar os artistas da "Geração 80", transformando uma característica supostamente negativa do grupo (ou seja, sua presumível filiação à transvanguardia internacional ${ }^{8}$ ) em um elemento de ligação com a "grande" tradição brasileira, o barroco. A estratégia de Pontual parece clara. Para qualquer crítico ligado a um nacionalismo mais aguerrido, a aderência de muitos artistas surgidos nos anos de 1980 à transvanguarda internacional poderia ser interpretada como um ponto negativo. Afinal, eles não passariam de mais um agrupamento de artistas brasileiros, sem nenhuma singularidade "local", que teriam se influenciado pela tendência mais recente da arte internacional.

O crítico dissolve essa visão quando associa o suposto pluralismo dos artistas dos anos de 1980 à transvanguarda para, imediatamente, alinhálo a um hipotético fundamento barroco que, para o autor, talvez espelhasse melhor do que qualquer outro "a experiência brasileira como um todo".

Ao estabelecer o liame dos artistas da "Geração 80" ao "fundamento barroco", Pontual marca um ponto em seu intuito de legitimação daqueles artistas. Afinal, tal estratégia significava conceder a eles uma dimensão de brasilidade que, em tese, desestabilizaria qualquer crítica à aderência daquele agrupamento à moda mais recente da cena artística internacional.

Há tempos existia no Brasil uma forte corrente de reflexão sobre a arte e a cultura brasileiras que entendia o conceito de barroco como fundamental e único para a compreensão da arte e da cultura aqui produzidas. Para essa corrente, toda a obra de arte ou produção cultural realizada no Brasil, para que de fato alcançasse a chancela de "brasileira" de maneira inquestionável, devia possuir sinais inequívocos de fundamentos barrocos ${ }^{9}$.

Se idealismo e romantismo eram as qualidades que faltavam à produção dos artistas brasileiros dos anos de 1970, eram justamente essas qualidades que, aos olhos de Roberto Pontual, sobravam e sobressaíam na produção dos jovens artistas da década de 1980.

Essa preocupação em destacar, em toda a produção brasileira e latino-americana, índices de características barrocas parece ter sido uma forte preocupação de Roberto Pontual. Na década de 1970, mais precisamente em 1978, o crítico organizou a exposição América Latina. Geometria Sensível, nas dependências do Museu de Arte Moderna do Rio de Janeiro (do qual era diretor na época), em que buscou detectar certo sabor "barroco" na produção brasileira e latino-americana, ligadas às tendências construtivas ${ }^{10}$. 
11. Esse costume de aliar à suposta espontaneidade e à expressividade do barroco brasileiro a "verdade" da arte brasileira, levará o crítico e professor Lourival Gomes Machado, entre os anos de 1950 e 1960, a se dedicar a um estudo aprofundado sobre as bases do barroco no Brasil (MACHADO, Lourival Gomes. Barroco Mineiro. São Paulo:

Ed. Perspectiva, 1978), problema que será percebido também na estrutura de suas críticas publicadas no jornal 0 Estado de S. Paulo contrárias à "impessoalidade" dos concretos brasileiros, como bem vem

estudando a pesquisadora

Ana Cândida Avelar, da Universidade de São

Paulo.

12. PONTUAL, Roberto. Op. cit., p. 61.

13. A capa do livro de Pontual leva um desenho de José Leonilson.

14. Ocorrido no Rio de Janeiro, em 1983, na galeria Thomas Cohn Arte Contemporânea, no Rio de Janeiro.
Neste sentido, Pontual se filia à vertente de críticos que, desde o início do século passado, intentava direcionar a produção brasileira para uma única orientação, e que teria como um dos pioneiros o escritor e crítico modernista Mário de Andrade.

Andrade acreditava ser o modernismo de 1922 a renovação e a continuidade da tradição barroca brasileira - mais "pura", "espontânea" e "expressiva" -, acesa de novo após o hiato da arte "acadêmica" do século XIX11.

Porém, o esforço de Roberto Pontual para legitimar a produção dos jovens artistas da "Geração 80" - em detrimento dos artistas da geração anterior - não para na tentativa de alinhá-los ao barroco. Pontual vai mais longe:

[...] Se ela estende a sua fome de olhar para fora do país e do continente e se, de longe ou de perto, por experiência direta ou por ouvir dizer, descobre na Europa e/ou nos EUA fontes irresistíveis de interesse [...], o mais importante a lhe dar vigor é, no entanto, a capacidade maiúscula que observo nela de assentar-se fundamentalmente sobre modelos endógenos. De aceitar e beber de preferência água nossa. E, por mais sorte ainda, os dois modelos que ela absorve em primeira linha são aqueles que melhor refletem o que eu chamaria de a polaridade essencial do espírito criador brasileiro: de um lado, ardente, o modelo antropofágico; do outro, ponderado, o modelo construtivo. Absorveos numa troca e numa concomitância como poucas vezes se viu tão avivada, oportuna e fértil entre nós $[\ldots]^{12}$.

Conectar esses artistas ao conceito de antropofagia e, ao mesmo tempo, ao "modelo construtivo" é, sem dúvida, o ponto alto de Explode Geração!. Barrocos e antropófagos, antropófagos e concretistas, os artistas da "Geração 80" ganharam a dimensão de guardiães do conceito de brasilidade nas artes visuais do país. Escrito no calor da hora, esse livro poderia até ser entendido como uma espécie de manifesto, travestido de texto analítico.

Após a análise geral sobre a arte brasileira pós-1964, Pontual dedica a última parte de seu livro a traçar breves perfis dos principais artistas que "explodiram" naquela década. Ali ele salienta os aspectos mais pitorescos de suas personalidades, o prazer com que realizavam suas produções e o caráter quase sempre lúdico, "antropofágico", "prazeroso" das mesmas.

O primeiro artista sobre o qual traçará comentários será José Leonilson que, para Pontual, seria o grande emblema da arte daqueles anos ${ }^{13}$.

$\mathrm{O}$ autor relata que em seu primeiro encontro com Leonilson ${ }^{14}$ notou conexões entre o trabalho do jovem artista com o do pintor uruguaio Torres-Garcia. Não o Torres-Garcia que teríamos nos acostumado a conhecer - aquele da "geometria sensível" -, mas o TorresGarcia que, entre 1928 e 1932, uniu "a simultaneidade das soluções pictóricas mais díspares" sem que, com isso, constituísse "um clima de 
15. PONTUAL, Roberto. Op. cit., p. 73.

16. Ibidem, p. 71. lesa-autenticidade” ${ }^{15}$. É interessante Pontual ter ido buscar numa fase da obra de Torres-Garcia (que, na época, Leonilson, segundo o crítico, dizia conhecer apenas "de nome"), a justificativa para o ecletismo que Leonilson experimentava na época. Um ecletismo, é importante afirmar, que poderia ser justificado, em primeiro lugar, pela extrema juventude do artista e, em segundo, pelo incentivo que poderia estar recebendo - e realmente estava, naquele período - dos influxos absorvidos nas correntes da pintura internacional (sobretudo a transvanguarda) que alimentava esse transitar tranquilo entre várias matrizes estilísticas.

Roberto Pontual, atento a essa questão, direciona o ecletismo de Leonilson para o âmbito do momento "pós-moderno" que se vivia na época. No entanto, para trazer a produção do artista para o terreno da "brasilidade" pretendida, o crítico de imediato associa o conceito internacional de "pós-moderno" àquele brasileiro de antropofagia, filiando, em definitivo, a produção de José Leonilson ao Brasil "quase pós-quepe", como o autor define o país no momento em que escreve o livro.

Antes, porém, de associar a prática de Leonilson a uma atitude pós-moderna, porém "antropófaga", o autor, em rápida análise dos procedimentos pictóricos do artista, já havia se esforçado a neles encontrar índices de síntese entre os aspectos "construtivos" e "barrocos" ou "afetivos". Índices que, como foi visto, haviam servido para que ele caracterizasse a "verdadeira" arte brasileira, na primeira parte de seu texto. É instrutiva esta descrição de Pontual:

[...] Nas grandes ou pequenas superfícies de tela, grosseiramente recortadas, sem a menor preocupação com o quadrado ou o retângulo perfeitos, desfiadas nos bordos, livres de chassis e pintadas a gestos imediatos, às vezes mal cobrindo as marcas de outros anteriores no mesmo pedaço de pano, cada trabalho de Leonilson armava um jogo com dois times de formas. As primeiras, puras, quase sempre sumárias na sua simples e flexível geometria, como alegres fragmentos soltos no ar prisioneiro do quadro. As segundas, maiores, maciças, imponentes, já designando coisas que a nossa lembrança do mundo podia facilmente nomear, mesmo na estranheza de sua nova configuração. Estas agiam sobre aquelas no sentido de dar-lhes a afetividade efetiva que a pura implantação geométrica mantivera até ali distante ou latente. No primeiro time, jogavam a forma e a cor; no segundo, o personagem, com o seu nome ou apelido e a sua história prontos a sair por todos os poros ${ }^{16}$.

Já na produção de Daniel Senise, Pontual notará a presença de influxos da obra de Cândido Portinari. Mesmo Senise negando tal filiação ou influência, Pontual não se furtará em escrever sobre o que poderia significar esse suposto resgate da obra portinaresca em plena década de 1980, na medida em que tal resgate poderia sugerir mais um índice do 
[...] Olhando e olhando, percebi que havia naqueles quadros uma presença inesperada: simplesmente, a de Portinari. Portinari, coitado, tão posto de lado, tão visto como um coroa sem interesse e sem graça pelas gerações que vêm aparecendo entre nós desde os anos 50 ou 60! [...] Cheio de dedos, perguntei a Daniel se ele tinha consciência da quase psicografia que os seus quadros iam evidenciando. Disse que não. Não importa, essas coisas acontecem mesmo quando se pensa e se diz que não, por defesa ou desconhecimento. Daniel, no fundo, não precisava preocupar-se, pois se Portinari viera frequentá-lo, assim sem cerimônia sobretudo o Portinari dos Retirantes e dos painéis dentro e fora da igreja da Pampulha - era muito menos por ele próprio do que pelo que significa a miscigenação estilística buscada na sua pintura. Ou seja, através do fantasma de Portinari, no qual se cruzam, bem ou mal, expressionismo, cubismo e surrealismo, o nosso Daniel de agora fecha mais uma vez o círculo. Come o comido, para tentar uma nova digestão, quem sabe mais feliz. O pretexto-Portinari, talvez passageiro nessa obra que apenas começa, lhe dá, contudo, o tom de comilança pátria que estava faltando na antropofagia da Geração 80 . Portinari, quem diria... [...] $]^{17}$.

De novo a imagem da antropofagia, dirigindo as leituras que Roberto Pontual realizava sobre a produção dos artistas surgidos nos anos de 1980.

De todos os artistas que Pontual cuidará em Explode Geração!, o único que não lhe desperta interesse positivo é Sérgio Romagnolo. Para Pontual, o artista, que pretendia "inutilizar o ilusionismo com outro ilusionismo, e subverter a leitura da imagem virtual com a própria imagem”, não o convencia. Para o autor:

[...] senti que a equação, no trabalho mesmo, terminava constantemente forçada demais, intelectualizada a um ponto tal que neutralizava toda a bagunça pretendida no coreto. São tantas e tão calculadas as saídas que ele tenta que a melhor porta continua fechada $[\ldots]^{18}$.

Para Pontual, interessado em encontrar uma produção descompromissada com qualquer tipo de programa, de atitude consciente perante a arte, as posturas de Romagnolo eram inadmissíveis por ferirem sua crença em uma produção pautada na "pura" emoção. Neste sentido, Romagnolo estava fora.

No entanto, no caso de Leda Catunda, o crítico, mesmo entendendo que a artista possuía um programa bastante próximo ao de Romagnolo, percebia que em suas produções os problemas eram resolvidos de maneira mais satisfatória, dentro dos esquemas que ele considerava compatíveis à nova pintura que então "explodia":

[...] Com Leda, não: as coisas correm bem, naturais e coerentes, entre ideias e obras [...] as vedações de Leda esgrimem com a imagem impressa, a imagem estampada, a indústria da imagem, a repetição 
O lúdico e o sério, o sério e o lúdico: outras maneiras de se referir ao "modelo antropofágico" e ao "modelo construtivo", e vice-versa. Tudo era válido nesse novo momento da arte brasileira. As sérias e sempre presentes preocupações de Sérgio Romagnolo em relação à natureza da arte e da pintura não podiam agradar ao crítico, tão preocupado em valorizar a suposta relatividade de conceitos que norteavam a produção da "Geração 80" no geral, e a produção de Leda Catunda, em particular. O "ludismo" de Leda era tão importante quanto o seu lado "sério". Esse era o tom principal do texto de Pontual sobre Catunda, refletindo um sentimento comum da crítica da época sobre o trabalho da artista.

$\mathrm{O}$ posicionamento de Pontual não permite que ele perceba que a produção de Leda Catunda, ao mesmo tempo em que se apresentava como uma das mais originais de sua geração, não deixava de trazer dados claros de sua filiação a determinados artistas da geração anterior. A então jovem artista, sempre atenta às ponderações de Romagnolo, desenvolvia uma tradução positiva para os estilemas típicos de sua época, os questionamentos presentes nas produções de artistas como Regina Silveira, Nelson Leirner e Julio Plaza que haviam sido seus professores na Fundação Armando Álvares Penteado (FAAP).

Creio que nessas considerações sobre Explode Geração! tenham sido alinhavadas as principais coordenadas do pensamento do autor sobre o suposto renascimento de uma arte brasileira típica, capaz de sintetizar matrizes tão opostas como o "método antropofágico" e o "método construtivo” em sua constituição.

Ter clara essa questão me parece fundamental para compreender o que foi levantado logo no início deste texto, ou seja, a capacidade de sobrevida do desejo de uma arte nacional no Brasil, mesmo depois de todas as experiências transformadoras passadas pela arte no país, desde o início dos anos de 1950 até meados da década de 1970.

Talvez a extrema valorização da "volta à pintura" nos anos de 1980 tenha propiciado, por sua vez, a "volta" a esse sentimento nativista percebido no texto de Pontual. Se em seus escritos da década anterior já era possível perceber esse seu interesse, talvez o advento de uma "nova figuração" aparentemente mais livre que a prática da geometria "sensível" que o sensibilizara antes, tenha lhe dado mais forças para um posicionamento como este.

A continuidade de estudos sobre a produção dos textos críticos de Roberto Pontual talvez possibilitem o entendimento mais amplo de suas filiações e interesses. 
Leda Catunda, Circulos,

1994, acrílica sobre tela

e tecidos, $137 \times 110 \mathrm{~cm}$

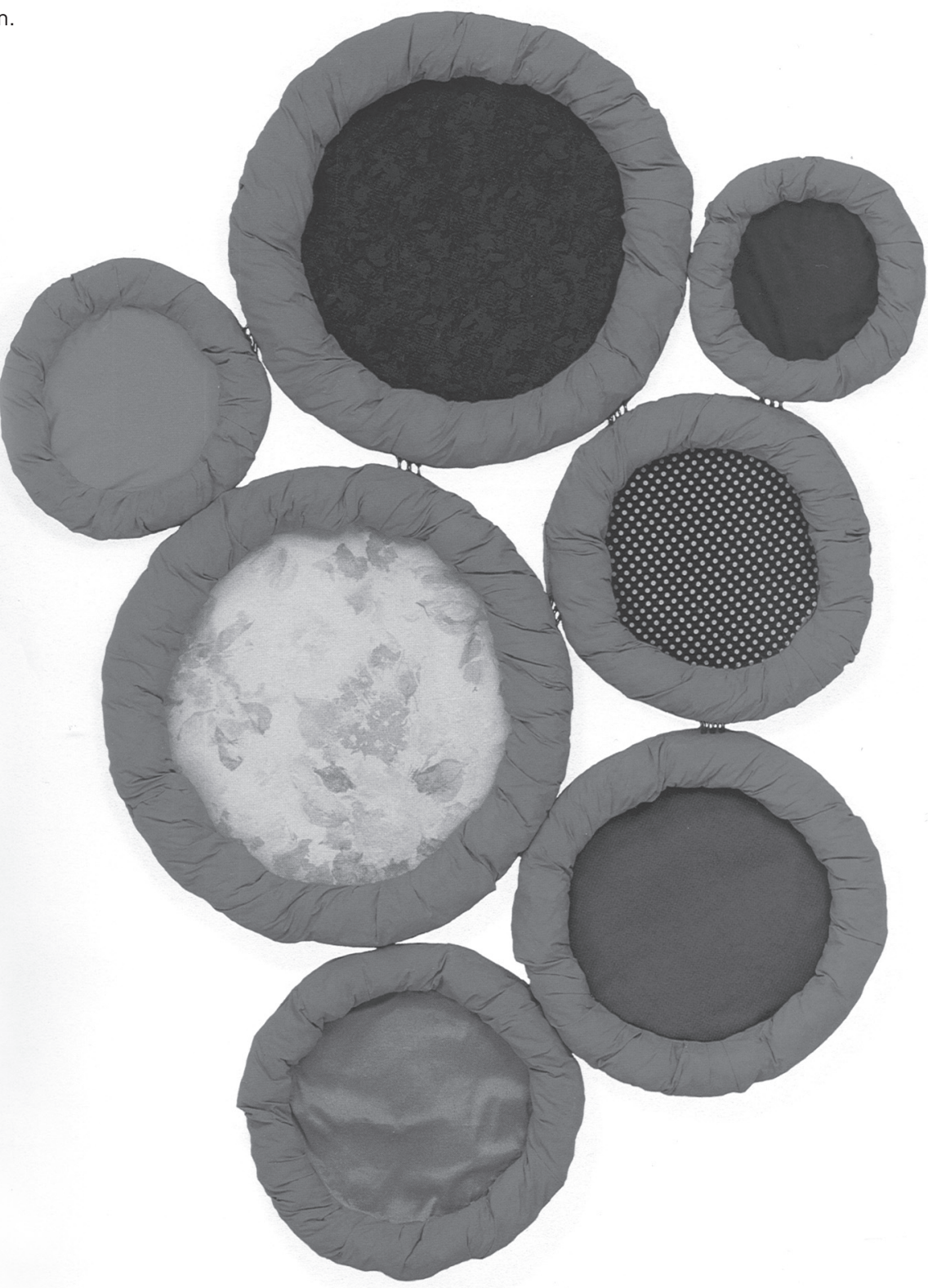

Tadeu Chiarelli é Professor Titular do Departamento de Artes Plásticas da ECA-USP e coordenador do Centro de Pesquisa de Arte \& Fotografia do Departamento de Artes Plásticas da ECA-USP. Atualmente é Diretor do Museu de Arte Contemporânea da Universidade de São Paulo (MAC-USP). 


\section{No próximo número artigos e ensaios de}

Andréa Tavares

Angela Varela

Cristian Borges

Gilbertto Prado

Jorge La Ferla

Julian Stallabrass

Laura Martin

Lucio Costa

Marco Giannotti

Pedro Arantes

ARS 16 | 2010 